\title{
Clinical and radiographic study of orofacial alterations in patients with systemic sclerosis
}

\begin{abstract}
Marcelo Marcucci ${ }^{(a)}$
Nitamar Abdala ${ }^{(b)}$
\end{abstract}

(a) PhD, Department of Stomatology and Oral \& Maxillo Facial Surgery, Heliópolis Hospital, São Paulo, SP, Brazil.

(b) PhD, Professor of Radiology, Department of Imaging Diagnostics, Federal University of São Paulo (UNIFESP), São Paulo, SP, Brazil.

\begin{abstract}
Systemic sclerosis (SS) is an autoimmune disease with great repercussions on the hard and soft tissues of the orofacial region. The aim of this study was to investigate the relationship between mandibular osteolysis and mouth opening measurements, duration of disease and presence/absence of teeth. Twenty-five subjects were selected: 15 diagnosed with systemic sclerosis and 10 healthy controls. The SS patients were grouped according to the presence (group I) or absence (group II) of mandibular osteolysis. The healthy subjects served as the control group (III). All of them underwent panoramic radiography on Ortophos $^{\circledR}$ equipment (Siemens) and were clinically examined, with mouth opening measurement. We observed that group I had a longer duration of the disease than group II $(\mathrm{p}=0.003)$. Groups I and II presented the same mean mouth opening. There was an increasing correlation between mouth opening and duration of the disease in group I ( $p=0.095)$, but this was not observed in group II $(\mathrm{p}=0.596)$. There was no correlation between presence/absence of teeth and osteolysis ( $\mathrm{p}>0.999$ ), or between presence/absence of teeth and side of osteolysis $(\mathrm{p}=0.143)$. We could conclude that osteolysis seemed to develop in patients with a longer duration of the disease, but did not modify the degree of mouth opening in relation to patients without osteolysis, and the presence/absence of teeth was not significant. On the other hand, in the osteolysis cases, the longer the duration of the disease, the greater the opening of the mouth.
\end{abstract}

Descriptors: Scleroderma, systemic; Clinical trial; Panoramic radiography.
Corresponding author:

Marcelo Marcucci

Rua Pirapora, 248, Paraíso

São Paulo - SP - Brazil

CEP: 04008-060

E-mail:marcucci21@gmail.com 


\section{Introduction}

Systemic sclerosis (SS) is a chronic inflammatory disease of unknown origin and autoimmune nature characterized by excessive deposition of collagen and glycosaminoglycans in the conjunctive tissue of the dermis and internal organs. ${ }^{1,2}$ It is a disease of low incidence, with an average of 4 to 19 new cases per million inhabitants and preferentially affects females $(4: 1){ }^{1}$ The age group most affected is between the third and fifth decades of life. ${ }^{3,4}$

Its etiopathogenesis has not been completely clarified. The conjunctive tissue undergoes a fibrosis process that is probably mediated by cytokines produced by lymphocytes and inflammatory cells, particularly the transforming growth factor beta (TGF- $\beta$ ). The microcirculation undergoes a process of primary vasculitis, which in conjunction with differing vessel thicknesses may cause total obliteration of the vessel due to collagen deposition, thereby leading to clinical manifestations of varying degrees of severity. ${ }^{1,2,3,5}$

This disease presents a variety of clinical features. Raynaud's phenomenon is usually its first manifestation, and skin thickening, esophageal dysmotility, restrictive pulmonary disease, pulmonary hypertension, arthralgia, myopathy, myocardiopathy and progressive renal insufficiency are also observed. ${ }^{1-3}$ The thickening of the skin (scleroderma) presents an initial phase of edema that makes the skin swollen and shiny, followed by a hardening phase in which the skin starts to have a dried-out, rough and inelastic appearance, and a third phase in which, in most patients, the skin gradually starts to take on an atrophied and thin appearance. ${ }^{1,3}$

The orofacial manifestations include stiffness and atrophy of the facial skin that gives the face a mask-like appearance; progressive limitation of mouth opening; skin and mucosa pigmentation (melanoleukoderma) and telangiectasia; hardening and loss of elasticity of the oral mucosa; hardening of the tongue and soft palate; varying degrees of xerostomy; periodontitis; and difficulty in chewing, speaking and swallowing. ${ }^{6-10}$

Radiographically, some characteristic alterations caused by systemic sclerosis are observed in the maxillomandibular complex, such as thickening of the periodontal ligament and areas of osteolysis in the mandible. These areas coincide with the insertion zones of the lateral pterygoid, temporal and, particularly, the masseter muscle. ${ }^{11}$

The aim of the present study was to correlate the clinical variables during the evolution of the disease, mouth opening measurements, presence/absence of teeth and presence/absence of mandibular osteolysis among patients with SS. By doing so, we might be able to find evidence enabling a better comprehension of the alterations to the stomatognathic system and, in the future, institute preventive and/or curative measures that could improve the quality of life of SS patients.

\section{Material and Methods}

For this study, which was developed in the Department of Imaging Diagnostics, Federal University of São Paulo (UNIFESP), 25 patients of both sexes were selected. Fifteen of these individuals (mean age $43.72 \pm 7.59$ years) had diffuse SS and the other ten (mean age $31.82 \pm 12.64$ years) were normal. Patients who presented SS in a limited form or in association with other rheumatic diseases were excluded. This study obtained prior approval by the Research Ethics Committee, UNIFESP.

All of the 25 subjects underwent oral clinical evaluation and panoramic radiography. The latter was performed on an orthopantomograph (Ortophos Plus PS ${ }^{\circledR}$, Siemens - Sirona Dental Company, Bensheim, Germany), working at $14 \mathrm{~mA}$ and variable $\mathrm{kVp}$ of 60.16 for women and 64.14 for men, at a mean magnification of $30 \%$. The images were interpreted by the examiner and the 15 patients were distributed into two groups according to the radiographic findings: with or without the presence of mandibular osteolysis (Figure 1).

Thus, a total of three groups were formed: group I, with 7 SS patients presenting mandibular osteolysis; group II, with 8 SS patients without mandibular osteolysis; and group III, with 10 healthy, normal individuals (control group). The patients with SS (groups I and II) were interviewed individually, to gather information such as gender, age, time when the first symptoms appeared and difficulties in opening their mouths. The length of time that they 
had had the disease was obtained from their medical records.

Following this, the patients underwent clinical examination to measure their mouth opening. In a comfortably seated position, with the head supported on a hard surface at $90^{\circ}$ to the floor, the patients were asked to open their mouths as wide as possible, three times. Each movement was measured, and only the largest measurement was used. The same procedure was used to obtain this measurement for the healthy individuals.

To make the measurements of maximum mouth opening, we used an adaptation of the linear interin-

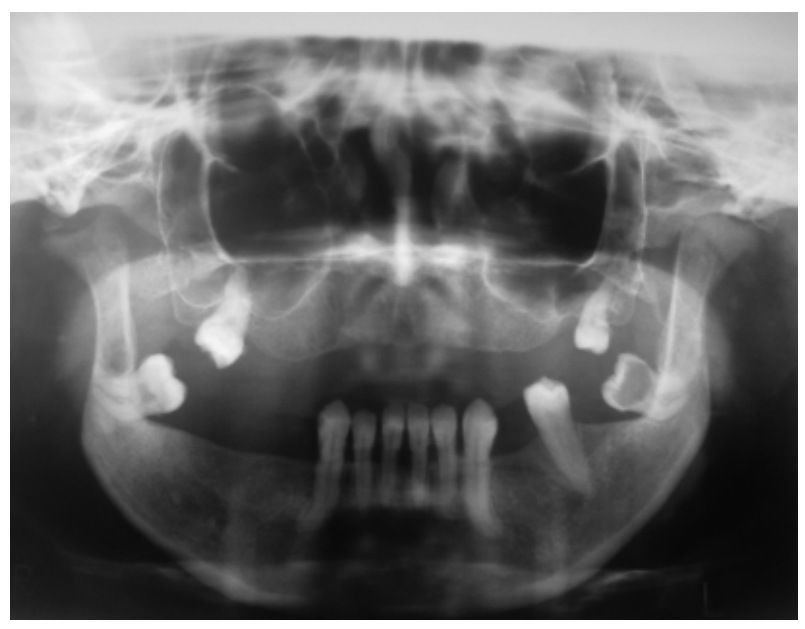

Figure 1 - Panoramic radiograph of the mandible presenting bilateral osteolysis of the angle, ascending branch and condyles. cisal distance method. ${ }^{12}$ The points of a dry-point compass were positioned on the middle third of the incisal aspect of the upper and lower right central incisors at maximum mouth opening, and this measurement was transferred to a ruler graduated in millimeters (Figure 2).

The patient was then asked to perform the intercuspidation movement, from which the vertical trespass distance was obtained and subtracted from the compass measurement. If the right central incisors were absent, the left central incisors, right lateral incisors or left lateral incisors would be used, in that order. For the inferential analysis of the clinical variables, Pearson's linear correlation coefficient, Student's $t$ test and Fisher's exact test were used. The rejection level adopted for the nullity hypothesis was $0.05(5 \%)$.

\section{Results}

The arithmetic mean and respective standard deviation for the age of the 25 patients was $39.71 \pm 7.91$ years. The results from the clinical variables studied among the patients with systemic sclerosis can be seen in Tables 1 and 2 .

Graph 1 shows the distribution of the groups in relation to the variable length of time with the disease. With the aim of investigating whether group I had had the disease for the same length of time as group II, Student's $t$ test was applied. The result from this showed that group I had had the disease

Figure 2 - Measurement of maximum mouth opening between teeth 11 and 41 .

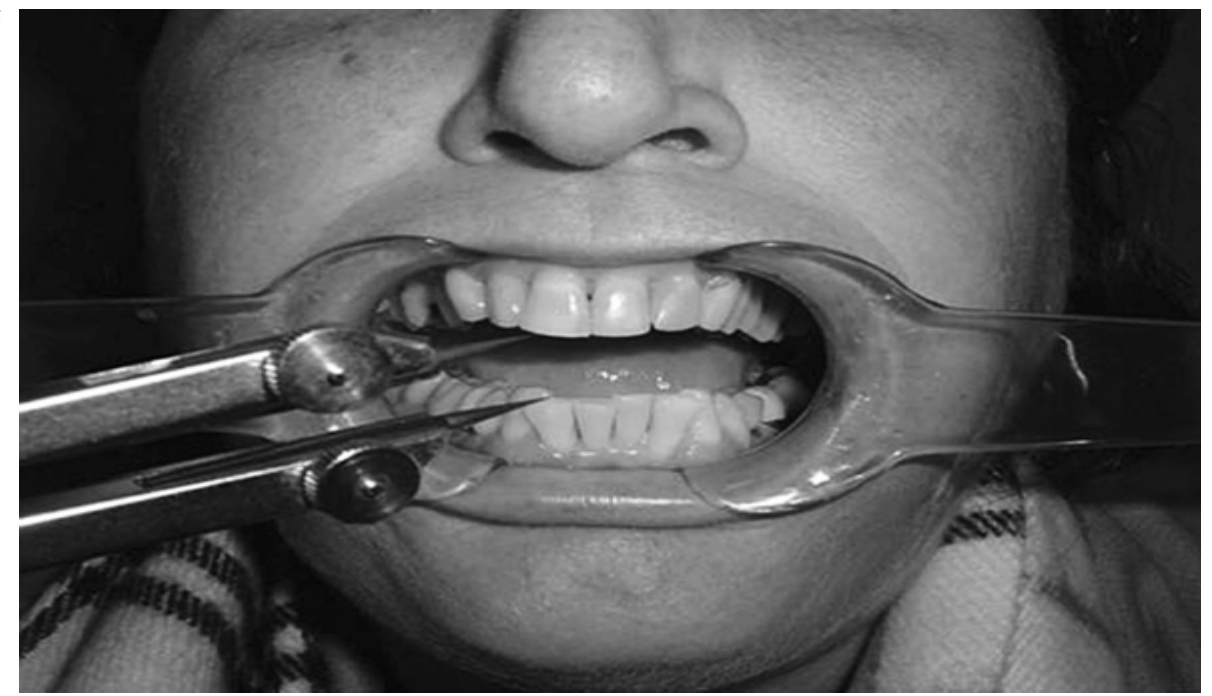


Table 1 - Clinical values of group I: patients with osteolysis.

\begin{tabular}{c|c|c|c|c|c}
\hline Patient & Gender & Age (y) & $\begin{array}{c}\text { Time of disease } \\
(\mathrm{y})\end{array}$ & $\begin{array}{c}\text { Mouth opening } \\
(\mathrm{mm})\end{array}$ & $\begin{array}{c}\text { Presence of } \\
\text { the teeth }\end{array}$ \\
\hline 1 & F & 44 & 9 & 32 & Total \\
\hline 2 & F & 38 & 7 & 34 & Partial \\
\hline 3 & F & 56 & 6 & 32 & Total \\
\hline 4 & M & 27 & 6 & 25 & Total \\
\hline 5 & F & 46 & 8 & 24 & Partial \\
\hline 6 & F & 47 & 5 & 25 & Partial \\
\hline 7 & M & 47 & 10 & 45 & Partial \\
\hline Mean (SD) & & $43.57(9.03)$ & $7.29(1.80)$ & $31(7.39)$ & \\
\hline
\end{tabular}

$\mathrm{SD}=$ standard deviation; $\mathrm{F}=$ female $\mathrm{M}=$ male $\mathrm{y}=$ years; $\mathrm{mm}=$ millimeters.

Table 2 - Clinical values of group II: patients without osteolysis.

\begin{tabular}{c|c|c|c|c|c}
\hline Patient & Gender & Age (y) & $\begin{array}{c}\text { Time of disease } \\
(\mathrm{y})\end{array}$ & $\begin{array}{c}\text { Mouth opening } \\
(\mathrm{mm})\end{array}$ & $\begin{array}{c}\text { Presence of } \\
\text { the teeth }\end{array}$ \\
\hline 8 & F & 35 & 7 & 23 & Partial \\
\hline 9 & F & 46 & 5 & 26 & Total \\
\hline 10 & F & 35 & 4 & 41 & Partial \\
\hline 11 & F & 47 & 7 & 44 & Total \\
\hline 12 & F & 52 & 8 & 38 & Partial \\
\hline 13 & F & 44 & 4 & 40 & Partial \\
\hline 14 & F & 43 & 6 & 27 & Total \\
\hline 15 & F & 49 & 5 & 49 & Total \\
\hline Mean (SD) & & $43.88(6.15)$ & $5.75(1.49)$ & $36(9.47)$ & \\
\hline
\end{tabular}

$\mathrm{SD}=$ standard deviation; $\mathrm{F}=$ female $\mathrm{M}=$ male $; \mathrm{y}=$ years $; \mathrm{mm}=$ milimeters.

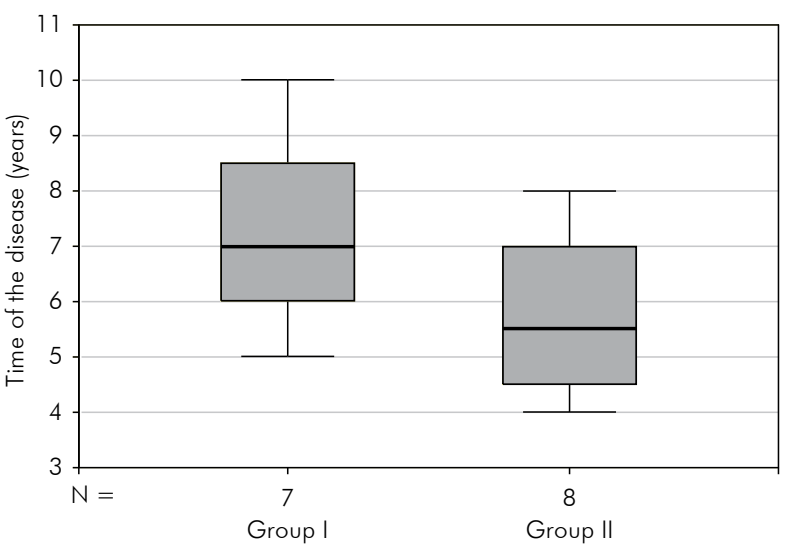

Graph 1 - Boxplot of time with the disease (years) according to the groups.

for a longer time than group II $(\mathrm{p}=0.003)$. The results relating to the variable of mouth opening measurements among the patients in groups I and II are shown in Graph 2. To compare the means between

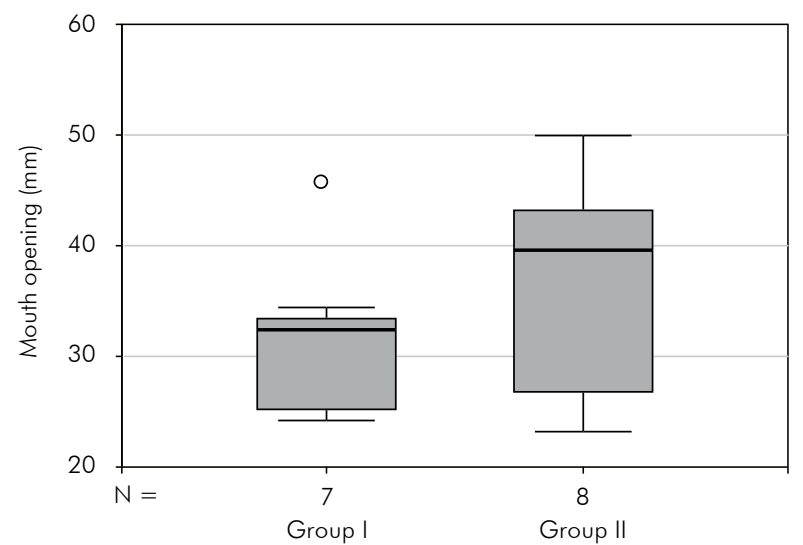

Graph 2 - Boxplot of mouth opening $(\mathrm{mm})$ according to the groups.

the two groups, Student's $t$ test was used. The result showed that the two groups had the same mean mouth opening $(\mathrm{p}=0.280)$.

The pattern of the relationship between mouth 


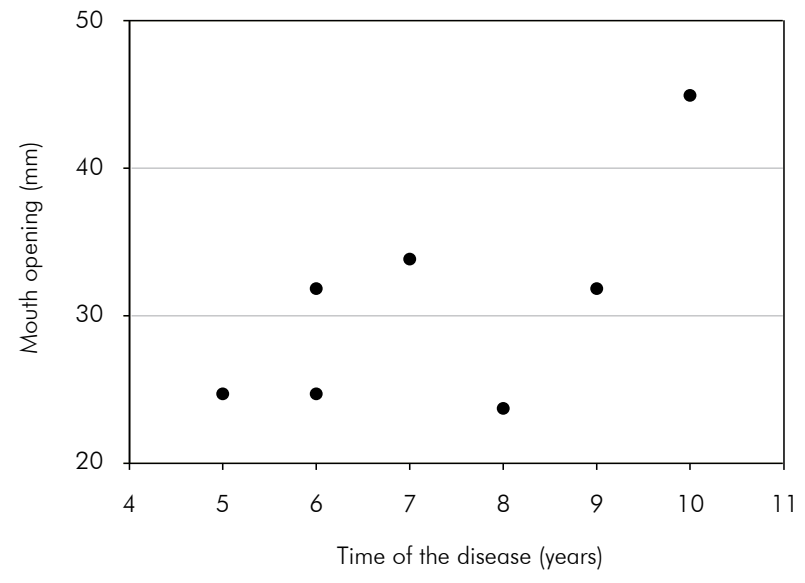

Graph 3 - Distribution of mouth opening and time of the disease: Group I.

opening and length of time with the disease according to the groups was investigated by estimating Pearson's linear correlation coefficient, as observed in dispersion plots. Pearson's linear correlation coefficient was found to be $0.676(\mathrm{p}=0.095)$, and therefore it was considered that for the individuals in group I there was a moderate increasing linear correlation between mouth opening and length of time with the disease (Graph 3). For group II, the distribution of information on mouth opening and length of time with the disease did not show any visual relationship (Graph 4). This was also confirmed by the finding that Pearson's linear correlation coefficient was $0.223(\mathrm{p}=0.596)$.

With regard to the presence of teeth, the patients were classified as possessing a full or a partial set of teeth. Patients were taken to have a partial set of teeth if they did not present a row of back teeth, which could be on one or both sides, in the upper and/or low jaw. Fisher's exact test for this association showed that there was no relationship between presence/absence of teeth and group ( $p>0.999)$.

\section{Discussion}

Limitation of mouth opening is a common finding in SS cases and is possibly related to the skin thickening that is characteristic of the disease. ${ }^{6,710,13,14}$ The progressive loss of elasticity of the cheeks and lips makes these regions hardened and causes a gradual decrease in the lip perimeter and

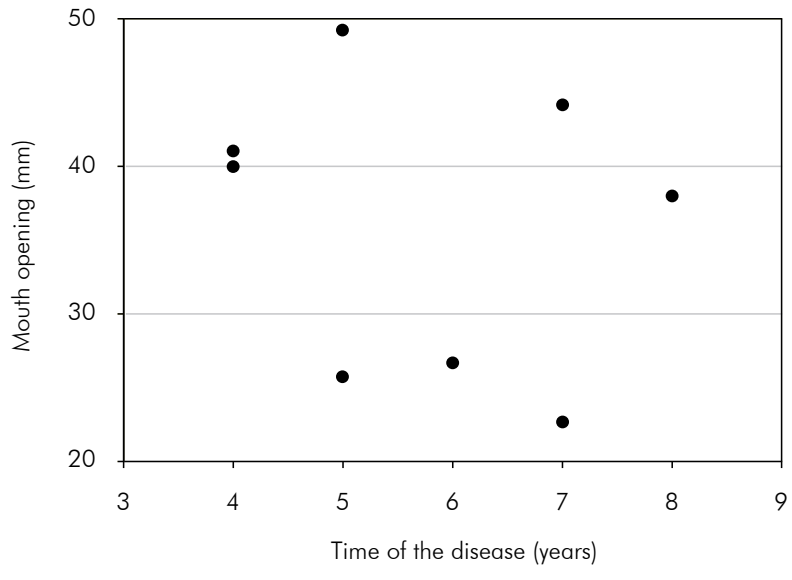

Graph 4 - Distribution of mouth opening and time of the disease: Group II.

maximum mouth opening. ${ }^{7}$ In our study, this limitation was the patients' main complaint in relation to the stomatognathic system, because of their difficulties in chewing or performing oral hygiene maneuvers, ${ }^{10}$ or even in relation to undergoing dental treatment. Some techniques involving active exercises have been indicated with some success in achieving expansion of the mandibular movements. ${ }^{7,13,14}$

Only a few studies have sought to objectively quantify this reduction in mouth opening in systemic sclerosis cases. ${ }^{6,10,15}$ In our study, a mean measurement of $47 \pm 5.1 \mathrm{~mm}$ was obtained among the healthy controls. Among the patients with osteolysis, the mean opening was $31 \pm 7.39 \mathrm{~mm}$, while among the patients without osteolysis, the mean was $36 \pm 9.47 \mathrm{~mm}$. In both the latter groups, the mean mouth opening was smaller than in the control group ( $\mathrm{p}=0.003$ and $\mathrm{p}=0.036$ respectively). Comparing only the two groups with SS, the group with osteolysis presented the same mean opening as did the group without osteolysis $(\mathrm{p}=0.280)$. These findings do not agree with those found in the literature, in which the patients with osteolysis presented a slight decrease in opening in relation to those without osteolysis. ${ }^{10,11}$

On the other hand, when the variable of length of time with the disease was analyzed, it was seen that the patients with osteolysis had a moderate tendency towards increased mouth opening over the course of the years $(\mathrm{p}=0.095)$, while among the pa- 
tients without osteolysis this trend was not observed ( $p=0.596)$. One possible explanation for this finding could be the fact that the most intense skin thickening occurs within the first 18 to 36 months of the disease, which is then followed by a variable period of stability, after which there is a slow and continuous decline, ${ }^{3}$ such that the skin takes on an atrophied and thin appearance.,16 Other factors, such as the number of patients studied, length of time with the disease and method used for measuring the mouth opening may cause variations in these results. ${ }^{6,17}$ In our sample, the patients reported transitory improvement following the use of an endovenous infusion of $2 \%$ lidocaine hydrochloride, which was used to attenuate the skin thickening. ${ }^{1}$

Previous studies did not find any direct relationship between the presence of osteolysis and the length of the course of the disease. ${ }^{6,11,18}$ However, osteolysis is detected between the fifth and seventh year after diagnosing SS. ${ }^{19}$ In our study, we observed that the patients with osteolysis presented a longer mean time with the disease $(7.29 \pm 1.8$ years $)$ than did the patients without osteolysis $(5.75 \pm 1.49$ years) $(\mathrm{p}=0.003)$. Considering that the systemic impairment caused by the disease is greater over the first five years of the disease ${ }^{1}$ and the skin involvement is most intense over the first three years, ${ }^{3}$ it can be inferred that the emergence of mandibular osteolysis may be related both to the peak of skin involvement and to the visceral involvement, since osteolysis tends to occur in patients with greater visceral involvement. ${ }^{19}$

The extent of the osteolysis was not quantified in our study but, rather, only its presence or absence. The rarity of the disease and the fact that mandibular osteolysis is present in a mean of $25 \%$ of the patients ${ }^{10,11,17,18}$ makes it difficult to standardize the

\section{References}

1. Kayser C, Andrade LEC. Esclerose Sistêmica. In: Sato E. Guias de Medicina Ambulatorial e Hospitalar - Reumatologia. São Paulo: Manole; 2004. p. 111-20.

2. Mayes MD, Lacey Jr JV, Beebe-Dimmer J, Gillespie B, Cooper $\mathrm{B}$, Timothy JL et al. Prevalence, incidence, survival and disease characteristics of systemic sclerosis in a large US population. Arthritis and Rheum. 2003;48(8):2246-55. grades of osteolysis. For this reason, the samples in the literature have included osteolysis to varying extents. ${ }^{6,17,18}$ Moreover, some patients with the disease for a long time may present only slight degrees of osteolysis, while others who have just had the disease for a short time may present great destruction. ${ }^{8}$

Concerning the presence/absence of teeth, the results showed that this was unrelated to the presence of osteolysis. That is, osteolysis may develop both in patients with a full set of teeth and in those with only a partial set $(p>0.999)$. This finding confirms the results from previous studies. ${ }^{17,18}$ In addition, we investigated the relationship between the side of the osteolysis and the presence/absence of teeth, and found that there was no association $(\mathrm{p}=0.143)$. We did not find any similar study with which we could compare or contrast this information.

We believe that new studies with different samples and methods are needed in order to bring out more evidence regarding the involvement of the stomatognathic system in patients with SS. Thus, longitudinal studies may provide predictive information about orofacial involvement in relation to the course of the disease.

\section{Conclusions}

According to our results, the patients with osteolysis presented longer times with the disease than did the group without osteolysis, but the presence of osteolysis did not influence the mouth opening measurement. We also observed that there was an increasing correlation between mouth opening and length of time with the disease among the patients with osteolysis, whereas this did not occur in the group without osteolysis. There was no relationship between presence/absence of teeth and osteolysis, or between presence/absence of teeth and side of osteolysis.

\footnotetext{
3. Marques Neto JF, Sampaio-Barros PD. Reumatologia: diagnóstico e tratamento. Rio de Janeiro: Medsi; 2000. p. 465-80.

4. Spackman GK. Scleroderma: what the general dentist should know. Gen Dent. 1999;47(6):576-9.

5. Sakkas LI. New developments in the pathogenesis of systemic sclerosis. Autoimmunity. 2005;38(2):113-6.
} 
6. Marmary Y, Glaiss R, Pisanty S. Scleroderma: oral manifestations. Oral Surg Oral Med Oral Pathol. 1981;52(1):32-7.

7. Naylor PW. Oral management of the scleroderma patient. JADA. 1982;105(5):814-7.

8. Ramón Y, Samra H, Oberman M. Mandibular condylosis and apertognathia as presenting symptoms in progressive systemic sclerosis. Oral Surg. 1987;63(3):269-74.

9. Weisman RA, Calcaterra TC. Head and neck manifestations of scleroderma. Ann Otol. 1978;87(3):332-9.

10. Wood RE, Lee P. Analysis of the oral manifestations of systemic sclerosis (scleroderma). Oral Surg Oral Med Oral Pathol. 1988;65(2):172-8.

11. Seifert MH, Steigerwald JC, Cliff MY. Bone resorption of the mandible in progressive systemic sclerosis. Arthritis and Rheum. 1975;18(5):507-12.

12. Wood GD, Branco JA. A comparison of three methods of measuring maximal opening of the mouth. J Oral Surg. 1979;37(3):175-7.

13. Defabianis P. Scleroderma: a case report of possible cause of restricted movement of the temporomandibular joint with effects on facial development. J Clin Pediatr Dent. 2003;28(1):33-8.
14. Pizzo G, Scardina GA, Messina P. Effects of a nonsurgical exercise program on the decreased mouth opening in patients with systemic scleroderma. Clin Oral Invest. 2003;7(3):175 8.

15. Nagy G, Kovacs J, Zeher M, Czirjak L. Analysis of the oral manifestations of systemic sclerosis. Oral Surg Oral Med Oral Pathol. 1994;77(2):141-6.

16. Akesson A, Fiori G, Krieg T, van den Hoogen FHJ, Seibold JR. Assessment of skin, joint, tendon and muscle involvement. Clin Exp Rheumatol. 2003;21(suppl. 29), S5-S8.

17. White SC, Frey NW, Blaschke DD, Ross MD, Clements PJ, Furst DE et al. Oral radiographic changes in patients with progressive systemic sclerosis. JADA. 1977;94(6):1178-82.

18. Ramirez JC, Cobos LS, Jelic PM. Reabsorción Osea Patológica de la Mandíbula y Ensanche Del Espacio Peridontal Dentário en Pacientes con Esclerosis Sistêmica. Rev Méd Chile. 1984;112(1):13-9.

19. Haers PE, Sailer HF. Mandibular resorption due to systemic sclerosis. Case report of surgical correction of a secondary open bite deformity. Int J Oral Maxillofac Surg. 1995;24(4):2617. 